\title{
Experimental investigation of heat transfer in a vertical annulus with a bottom heated rotating inner cylinder
}

\author{
Muhammad F. Ejaz*, Shehryar Manzoor \\ Mechanical Engineering Department, University of Engineering \& Technology, Taxila 47050, Pakistan
}

Corresponding Author Email: engr.farhan8170@gmail.com

https://doi.org/10.18280/ijht.360240

Received: 5 March 2018

Accepted: 2 April 2018

\section{Keywords: \\ experimental investigation, heat transfer, heat transport mechanisms, vertical annulus, buoyancy-driven flow, rotating inner cylinder}

\begin{abstract}
Due to several engineering applications of heat transfer in confined enclosures, it has been an attractive topic for the researchers. The presented research is also an important contribution in this massive research area. Effects of a bottom heated rotating cylinder in a vertical annulus has been experimentally studied with respect to heat transfer parameters. Bottom heating of inner cylinder triggers a buoyancy-driven flow of air within the annulus and heat transfer due to this heating is studied against the rotation of the inner cylinder. Thus, a simultaneous effect of bottom heating and rotation of inner cylinder on heat transfer is inspected. The experimental setup of presented research consists of two seamless mild steel cylinders, a mild steel bottom heating plate, wireless data acquisition system and a rotational mechanism for the inner cylinder. A series of experiments are carried out for bottom heated plate temperature ranging from $313 \mathrm{~K}$ to $333 \mathrm{~K}$ and rotational Reynolds number of inner cylinder from $0-1660$. The experimental results are presented in the form of a quantitative analysis of measured steadystate temperatures and non-dimensional parameters of heat transfer such as local Nusselt number, local Rayleigh number and $\mathrm{Gr} / \mathrm{Re}_{\Omega}{ }^{2}$. It is noted that the rotation of inner cylinder is effectual to enhance the heat transfer within the annulus by altering heat transport mechanisms. Moreover, the rotational effects deteriorate the influence of buoyancy at high rotational Reynolds number.
\end{abstract}

\section{INTRODUCTION}

Heat transfer through different annuli and enclosures has been a topic of research for decades. Applications of heat transfer in annuli can be found in engineering fields like aerospace industry, heat exchangers, process industry, nuclear reactors, cement industry, furnace designs, electro-mechanical systems etc. [1-2]. Therefore, many efforts have been made to study and control the heat transport mechanisms within the annuli. Some common techniques used to influence the heat transfer parameters within the annuli comprised of variations of various factors such as configurations, rotatory motion, materials, radius ratios, eccentricities etc. Moreover, the sizes, locations and configurations of the heating element are also some major factors that can affect the heat transfer in enclosures.

Researchers [3-11] focused on the heat transfer parameters within annuli subjected to different conditions and working fluids. Firstly, a study of Kee et al. [3] on natural convection heat transfer is considered. They studied heat transfer due to heat generating fluid within closed vertical cylinders and proposed a generalized correlation for average $\mathrm{Nu}$ as function of modified Gr. Similarly, Keyhani et al. [4] performed an experimental investigation on natural convection in a vertical annulus by keeping inner cylinder at constant heat flux while the outer cylinder at constant wall temperature. Their results suggested that the enclosure geometry and Ra have more tendency to affect the flow fields and heat transfer as compared to radius ratio and Pr. Lipkea and Springer [5] experimentally tested heat transfer within a vertical annulus filled with helium, neon and argon gases. Heat sources were placed at different locations in the annulus and characteristics recirculation velocity of gases was analyzed with respect to heat transport mechanisms. It was observed that conduction was the only mode of heat transfer below certain Ra and aspect ratio (L/D). In another study, Malik et al. [6] experimentally investigated the effects of materials, diameters of the inner cylinder and bottom disk temperatures on non-dimensional parameters of heat transfer. They considered a bottom heated vertical concentric cylindrical enclosure for the study. A numerical study for free convection in a vertical porous annulus was presented by Sankara et al. [7]. The annulus was heated discretely while the outer walls were kept at a low isothermal temperature. The study pointed out that the heat transfer rate was highly dependent on size and location of the heating element as well as radius ratio of the annular cavity. An experimental study of free convection in an open-ended, vertical and concentric annulus was presented by Alipour et al. [8]. They observed that the radius ratio of the annulus related inversely to $\mathrm{Nu}$, moreover their research also discovered that average $\mathrm{Nu}$ is more dependent on $\mathrm{Ra}$ at high radius ratio. Another study on forced convection heat transfer in an eccentric vertical annulus by Hosseini et al. [9] indicated that increasing inlet air velocities and eccentricities for the annulus boosted the heat transfer within the vertical annulus/

Mohammed \& Antonio [10] experimental investigated the thermal entry region of a horizontal concentric annulus. Their investigations revealed that the $\mathrm{Nu}$ values were significantly higher in entry region as compared to fully developed combined convection region. A review of the buoyancy-driven 
flows inside horizontal cylindrical configurations was authored by Angeli et al. [11]. Both numerical and experimental studies were considered. The review was critical with respect to flow regimes, temperature pattern, bifurcative phenomenon, instabilities and their linkages with relevant dimensional and non-dimensional parameters. The influence of eccentricity of the inner cylinder on the thermal assets and laminar flow was also a part of their review. They pointed out that a rich diversity in steady-state solutions. Moreover, radius and position of the inner cylinder also showed a significance standing in the study of heat transfer and flow geometry inside the horizontal enclosures.

Similarly, Table 1 summarizes some of the important contributions of past researchers related to heat transfer within enclosures due to a rotating inner cylinder.

Table 1. Heat transfer within the enclosures due to the rotating inner cylinder

\begin{tabular}{|c|c|c|c|}
\hline Authors & Configuration & $\begin{array}{c}\text { Investigation } \\
\text { Type } \\
\end{array}$ & Outcomes \\
\hline $\begin{array}{l}\text { Jeng et al. } \\
\quad[12]\end{array}$ & $\begin{array}{l}\text { Rotating inner cylinder in a } \\
\text { long horizontal concentric } \\
\text { annulus. }\end{array}$ & Experimental & $\begin{array}{l}\text { Rotational responses of the inner cylinder on heat transfer and flow } \\
\text { characteristics in an annular channel were tested. Their major finding } \\
\text { was to point out a quick increase of Nu in presence of axial flow and a } \\
\text { decrease in this effect at higher } \operatorname{Re}_{\Omega} \text {. }\end{array}$ \\
\hline $\begin{array}{c}\text { Astill } \\
{[13]}\end{array}$ & $\begin{array}{l}\text { Rotating inner cylinder in a } \\
\text { horizontal concentric annulus. }\end{array}$ & Experimental & $\begin{array}{l}\text { The research investigated the parameters influencing the flow properties } \\
\text { and heat transfer in air gap within the annulus having a rotating inner } \\
\text { cylinder. In case of rotation of the inner cylinder, length of developing } \\
\text { flow was increased which caused turbulence and consequently enhanced } \\
\text { the heat transfer. }\end{array}$ \\
\hline $\begin{array}{l}\text { Ball et al. } \\
\quad[14]\end{array}$ & $\begin{array}{l}\text { Rotating inner cylinder in a } \\
\text { vertical } \\
\text { concentric annulus. }\end{array}$ & Experimental & $\begin{array}{l}\text { Their major findings were about the relationship of the radial gap } \\
\text { between the cylinders and effects of } \operatorname{Re}_{\Omega} \text {. They concluded that more } \\
\text { pronounced the cylindrical radial gap, more it opposed the effects of } \\
\qquad \operatorname{Re}_{\Omega} \text { on heat transfer. }\end{array}$ \\
\hline $\begin{array}{l}\text { J.Lee et al. } \\
\qquad[15]\end{array}$ & $\begin{array}{c}\text { Stationary and Rotating Vertical } \\
\text { Annulus }\end{array}$ & Experimental & $\begin{array}{l}\text { The annulus was filled with a stably-stratified salt-water solution. The } \\
\text { main objective of the study was to gather information about the } \\
\text { parameters influencing free convection with time. These parameters } \\
\text { included temperature, rotating velocity and concentration gradients. } \\
\text { They also showed the effect of rotation on the development of a multi- } \\
\text { layered flow and different field variables. According to their results, } \\
\text { rotation effects caused a delay in the development and merging of fluid } \\
\text { layers. }\end{array}$ \\
\hline $\begin{array}{l}\text { Fu et al. } \\
\quad[16]\end{array}$ & $\begin{array}{l}\text { Square Enclosure with rotating } \\
\text { cylinder at the center having } \\
\text { adiabatic top and bottom walls } \\
\text { while the temperature of left } \\
\text { wall was higher than the right } \\
\text { wall. }\end{array}$ & Numerical & $\begin{array}{l}\text { Newton-Raphson algorithm with a penalty finite element method was } \\
\text { used to solve the governing equations with boundary conditions. } \\
\text { According to their results, the direction of rotation was an important } \\
\text { factor for heat transfer enhancement in their enclosure; heat transfer } \\
\text { enhancement of counterclockwise rotation was more significant as } \\
\text { compared to clockwise rotation. }\end{array}$ \\
\hline $\begin{array}{l}\text { A. } \\
\text { Misirlioglu } \\
\text { [17] }\end{array}$ & $\begin{array}{l}\text { 2-D Square cavity filled with a } \\
\text { rotating cylinder was placed at } \\
\text { the center. }\end{array}$ & Numerical & $\begin{array}{l}\text { This investigation was done for a square cavity filled with a clear fluid } \\
\text { and different porous fluids having different Darcy numbers. They } \\
\text { observed that the effect of Darcy number on heat transfer diminished at } \\
\qquad h \operatorname{high}_{\Omega} \text {. }\end{array}$ \\
\hline $\begin{array}{l}\text { Roslan et } \\
\text { al. }[18]\end{array}$ & $\begin{array}{l}\text { Rotating cylinder at the center } \\
\text { of a } 2-\mathrm{D} \text { square enclosure whose } \\
\text { top and } \\
\text { bottom walls were adiabatic } \\
\text { while the left wall was hotter } \\
\text { than the right. }\end{array}$ & Numerical & $\begin{array}{l}\text { Various nanofluids were used as working substance for this research. A } \\
\text { relatively slow rotation in a positive direction, high nanoparticle } \\
\text { concentration and moderate size cylinder in the center of the enclosure } \\
\text { were pointed out as major factors which enhance heat transfer within the } \\
\text { enclosure. }\end{array}$ \\
\hline
\end{tabular}

This study examined steady-state mixed convection with respect to different heat transfer parameters such as $\mathrm{Pr}, \mathrm{Ra}$ and aspect ratio (L/D) between the cylinders. Authors found out that the mean $\mathrm{Nu}$ decreased

Liao and The heated rotating cylinder in a Lin [19] 2-D square enclosure.
Numerical with increasing aspect ratio. The study also covered the effects of heat transport mechanisms within the enclosure and revealed the main source of heat transfer was conduction when $\mathrm{Ra}=10^{4}$. Furthermore, Nu became independent of $\mathrm{Ra}$ when $\mathrm{Gr} / \mathrm{Re}_{\Omega}{ }^{2}$ value went below the unity.
Parocini et al. [20], Aydin and Yang [21], Kuznetsov and Shermet [22] worked on factors influencing the heat transfer parameters within the rectangular and square enclosures. Effect of the localized heating source on free convective heat transfer in a square enclosure was investigated by Paroncini et al. [20]. A double exposure holographic interferometry technique was used for the analysis. The results exhibit the effect of Ra on the development of natural convection currents within the enclosure. A comparison of numerical and experimental results was also presented in the study. In another study, Aydin and Yang [21] investigated free convection in bottom heated 2-D rectangular enclosures. A balanced cooling was applied to the outer walls of the enclosure. The study pointed out the dependency of heat transfer mode on $\mathrm{Ra}$ and a presented a relation of $\mathrm{Nu}$ with $\mathrm{Ra}$ for the bottom portion of the cylinder. Kuznetsov and Shermet [22] presented a numerical transient investigation of conjugate free convection in a 2-d rectangular enclosure. Like previous studies, they found that the size and location of the heat source as an important factor which altered the flow and temperature 
profiles of the enclosure. Moreover, the study also unearthed the formation of a thermal plume within the enclosure at high Gr.

Similarly, some studies [23-25] related to heat transfer due to a rotating cylinder in the open atmosphere is also reviewed. In this regard, a numerical study on rotating cylinder by Kang et al. [23] is presented. The study comprised of a stimulated laminar flow across a rotating cylinder in both directions. The results were critical with respect to flow geometry across the rotating cylinder and found out a direct relation of lift coefficient with the rotational number while an inverse relation of drag coefficient with rotational number. Similarly, the effect of rotating cylinder placed horizontally in the quiescent air was experimentally investigated by Ozerdem [24]. In their results, average $\mathrm{Nu}$ came out to be directly related to the rotational speed. Heat transfer across a rotating cylinder with constant rotation rates was experimentally studied by Paramane and Sharma [25]. They used radiation pyrometer to measure average convective heat transfer coefficients. Their study revealed that increasing rotation speed results in an increase of $\mathrm{Nu}$ within a given range of $\mathrm{Re}_{\Omega}$.

As mentioned in above studies, a plenty of experimental and numerical research has been conducted on heat transfer in enclosures. Researchers have focused on vertical and horizontal cylinders, vertical and horizontal annuli, concentric and eccentric annuli, rotating and stationary cylinders placed in different types of cavities using different working fluids. Despite these researches, the subject of present study i.e. the effect of rotation on heat transfer in within a vertical concentric cylindrical annulus is still to be investigated. Keeping in view the considerable research potential, the experimental setup of presented research was made. Moreover, the presented work is not only unique, but it can also serve as a guide and unlock a wide area of research for the future researchers in the field of heat transfer.

\section{EXPERIMENTAL SETUP AND PROCEDURES}

The experimental setup of this research was carefully planned and shaped to study the influence of base temperatures and rotation of the inner cylinder on heat transfer within the vertical annulus. The experimental setup can be seen in Figure 1. Further description of some of the major components of the experimental model is following:

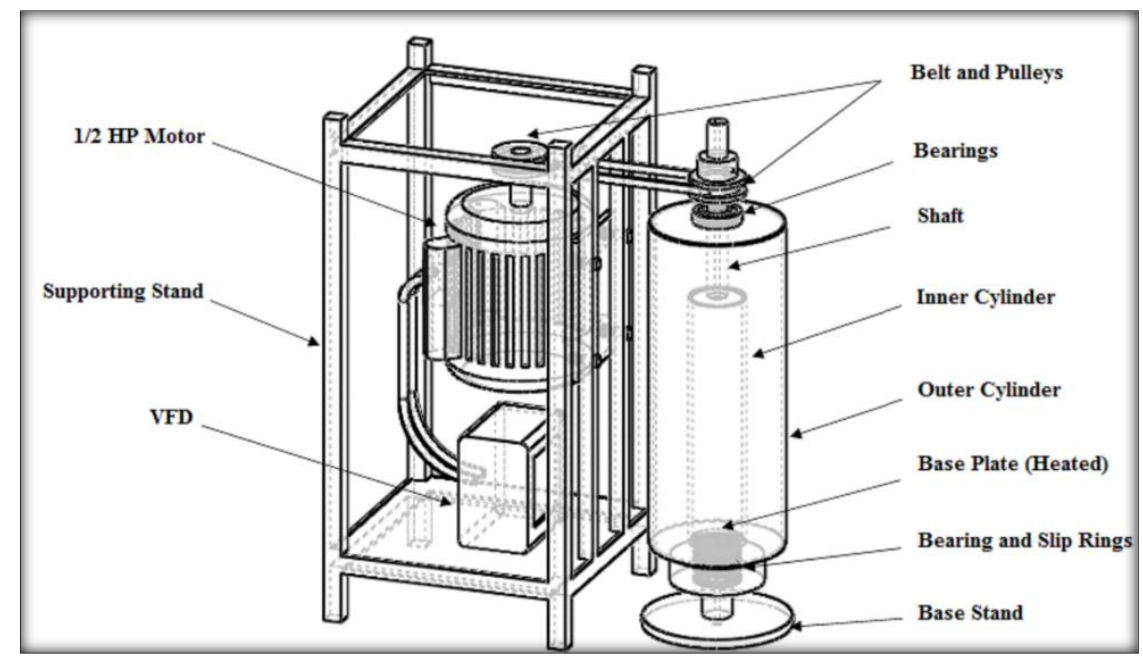

Figure 1. Experimental setup

\subsection{Annulus}

The annulus under study consisted of two seamless vertical concentric cylinders with different diameters; the inner cylinder was bottom heated, rotating and shorter in length and diameter than the stationary outer cylinder, the arrangement of cylinders can be seen in Figure 1. Temperature sensors (LM35) were applied across the outer surface of the inner cylinder and the inner surface of the outer cylinder. Schema of sensor distribution on the inner cylinder can be seen in Figure 2, while temperature sensors on outer cylinder were placed exactly parallel to the sensors on the inner cylinder. Scheme applied here was optimum to get a temperature sense of the whole enclosure. The inner cylinder also contained a heating element at the bottom. This element was a mild steel disc plate attached to a $300 \mathrm{~W}$ plate type heater. Moreover, the top and bottom lids of the enclosure were properly insulated using asbestos sheets. The properties and geometrical specifications of both cylinders and bottom disc are given in Table 2.
Table 2. Geometric specifications and properties of the annulus

\begin{tabular}{|c|c|c|c|}
\hline Property & $\begin{array}{c}\text { Inner } \\
\text { Cylinder }\end{array}$ & $\begin{array}{c}\text { Outer } \\
\text { Cylinder }\end{array}$ & $\begin{array}{c}\text { Bottom } \\
\text { Disc }\end{array}$ \\
\cline { 1 - 2 } Material & Mild Steel & Mild Steel & Mild Steel \\
\cline { 1 - 2 } $\begin{array}{c}\text { Thermal } \\
\text { Conductivity }\end{array}$ & 45.3 & 45.3 & 45.3 \\
\cline { 1 - 2 }$(\mathbf{W} / \mathbf{m}-\mathbf{K})$ & \multirow{2}{*}{$\mathrm{D}_{\mathrm{i}}=0.0755$} & $\mathrm{D}_{\mathrm{o}}=0.1524$ & 0.0712 \\
\cline { 1 - 3 } $\begin{array}{c}\text { Diameter } \\
(\mathbf{m})\end{array}$ & 0.004 & 0.005 & 0.006 \\
\cline { 1 - 2 } $\begin{array}{c}\text { Thickness } \\
(\mathbf{m})\end{array}$ & $\mathrm{L}_{\mathrm{i}}=0.38$ & $\mathrm{~L}_{\mathrm{o}}=0.408$ & - \\
\cline { 1 - 3 } Height (m) & &
\end{tabular}

Two temperature sensors were mounted at the central upper surface of the disk. The temperature of the bottom disc was controlled by a programmable relay type temperature controller. This controller measures the surface temperature of the bottom disc and regulates its temperature by tripping the 
heater when the temperature exceeds the required limit and then turning it on when the temperature goes below the limit.

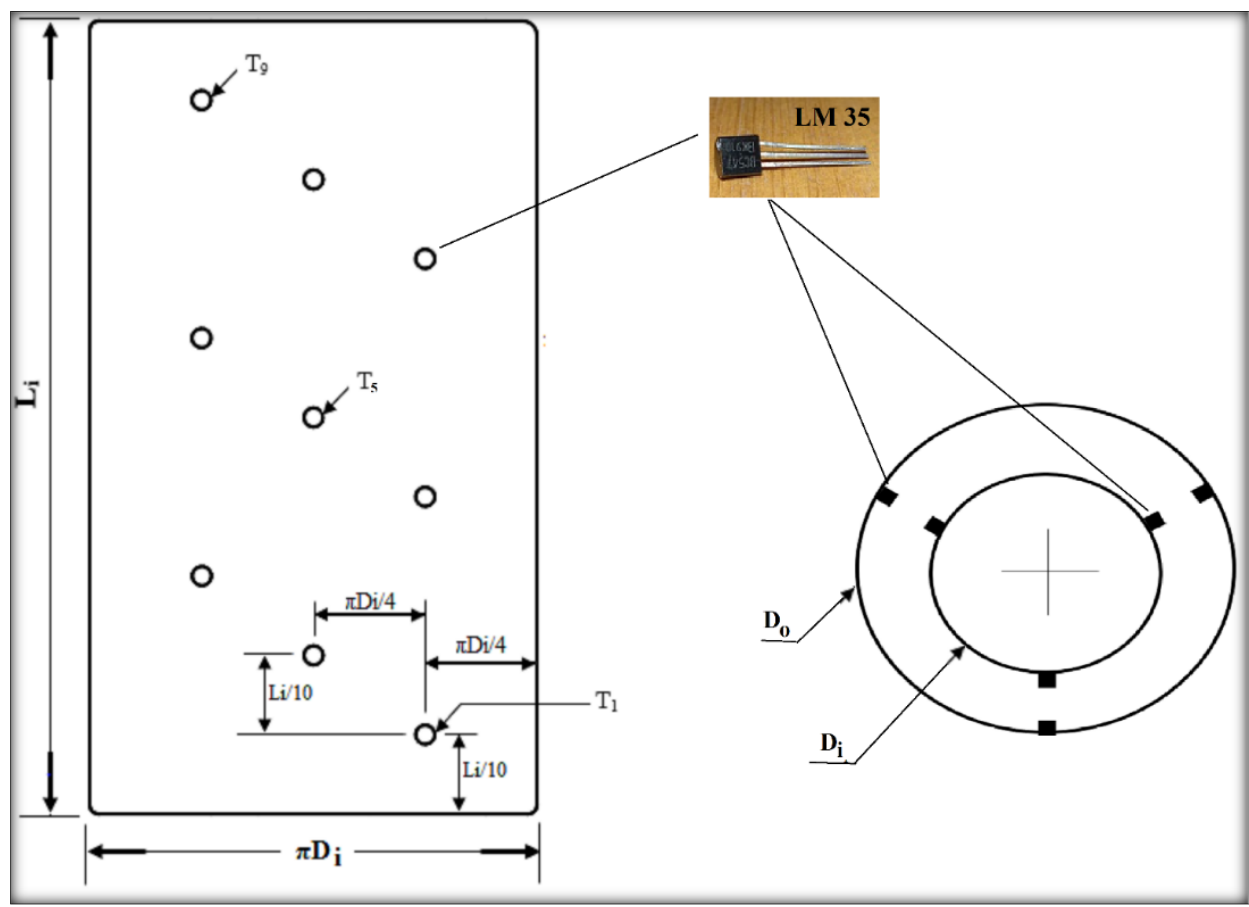

Figure 2. Positions of temperature sensors

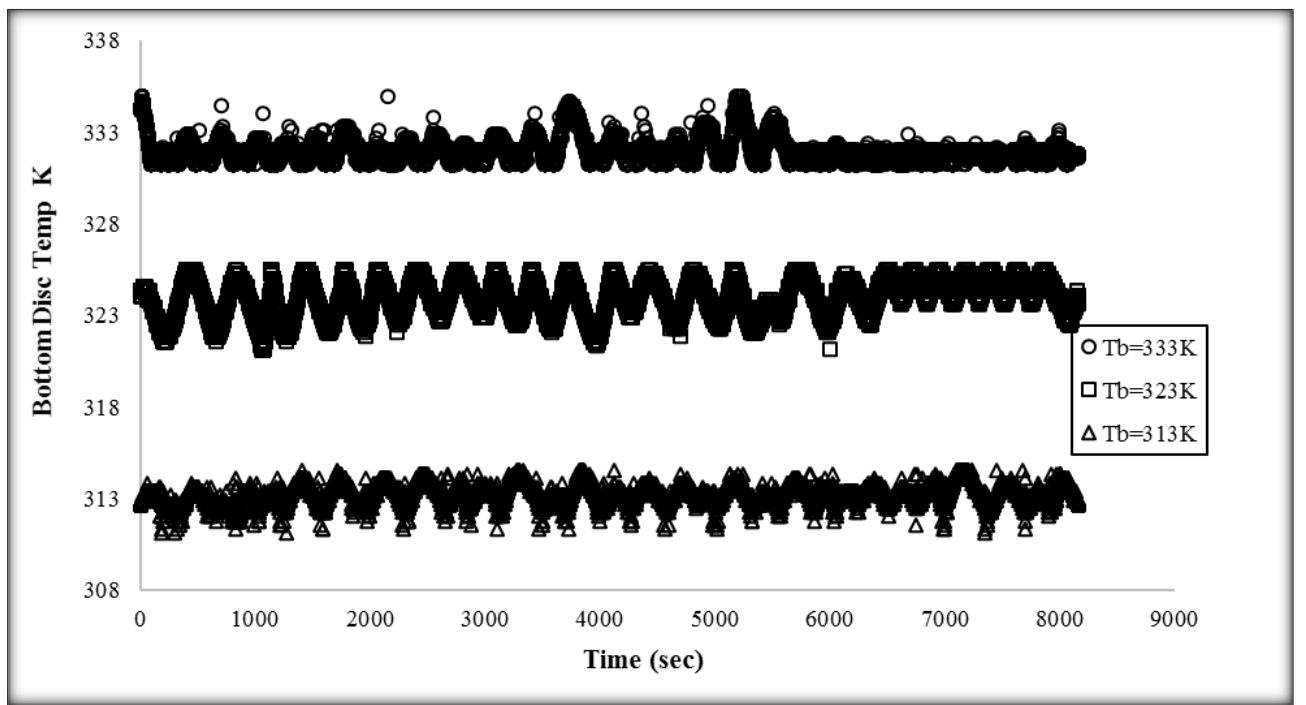

Figure 3. Evolution of bottom disc temperature with time

\subsection{Data acquisition}

Temperature sensors (LM-35) used in the research were Integrated Circuit precision temperature sensor. These sensors give output directly in Centigrade temperature scale. Due to the complexity of this experimental setup a wireless data acquisition system was designed to extract the results of the experimentation. LM-35 temperature sensors were connected to an Arduino Mega microcontroller which was further integrated with a wireless device Zigbee. Zigbee is a low power device using the wireless mesh network to transmit data between a receiver and transmitter. The setup was designed with the help of temperature measurement methods used by [26-28].

\subsection{Other equipment}

An electric motor was used to rotate the inner cylinder. The motor was coupled with the inner cylinder through a beltpulley mechanism as shown in Figure 1. The motor was controlled by a VFD; this device was used to rotate the motor at different frequencies which subsequently moved the inner cylinder at different RPMs. The RPMs of the inner cylinder was measured by a non-contact laser tachometer. A heavy base support riveted in the ground was used to support the assembly and to minimize the vibrations due to the rotation. A heavy cast iron structure was used to support the motor and VFD assembly as shown in Figure 1. Further detail of the equipment is given in Table 3. 
Table 3. Equipment details

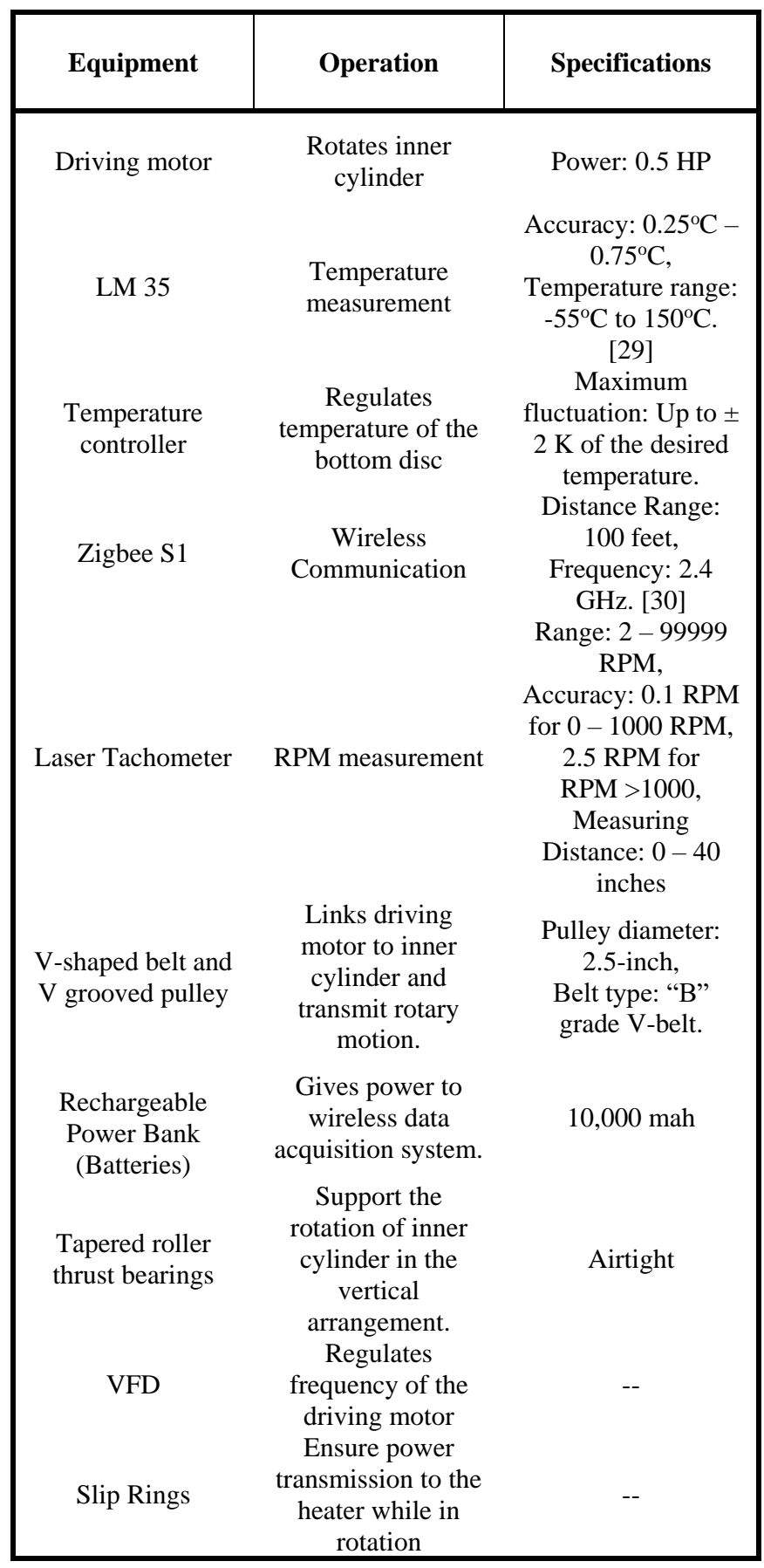

\subsection{Experimental procedures}

Figure 4 summarizes the experimental methodology of this research. Initially, the inner cylinder was rotated, and its RPMs were regulated by a VFD coupled with the driving motor. At the same time, the heater was turned on and bottom plate temperature was regulated using a temperature controller. The temperature of the bottom disc was recorded and regulated after every 0.25 second. Bottom disc temperatures for one set of experiments is shown in Figure 3. In the end, temperatures of the cylindrical walls were noted after every 15 seconds and recorded when the steady state was achieved. The steady-state condition was assumed in the enclosure when temperature values remained steady for at least ten minutes. To reduce errors and obtain reliable results, all experiments were repeated at least three times.

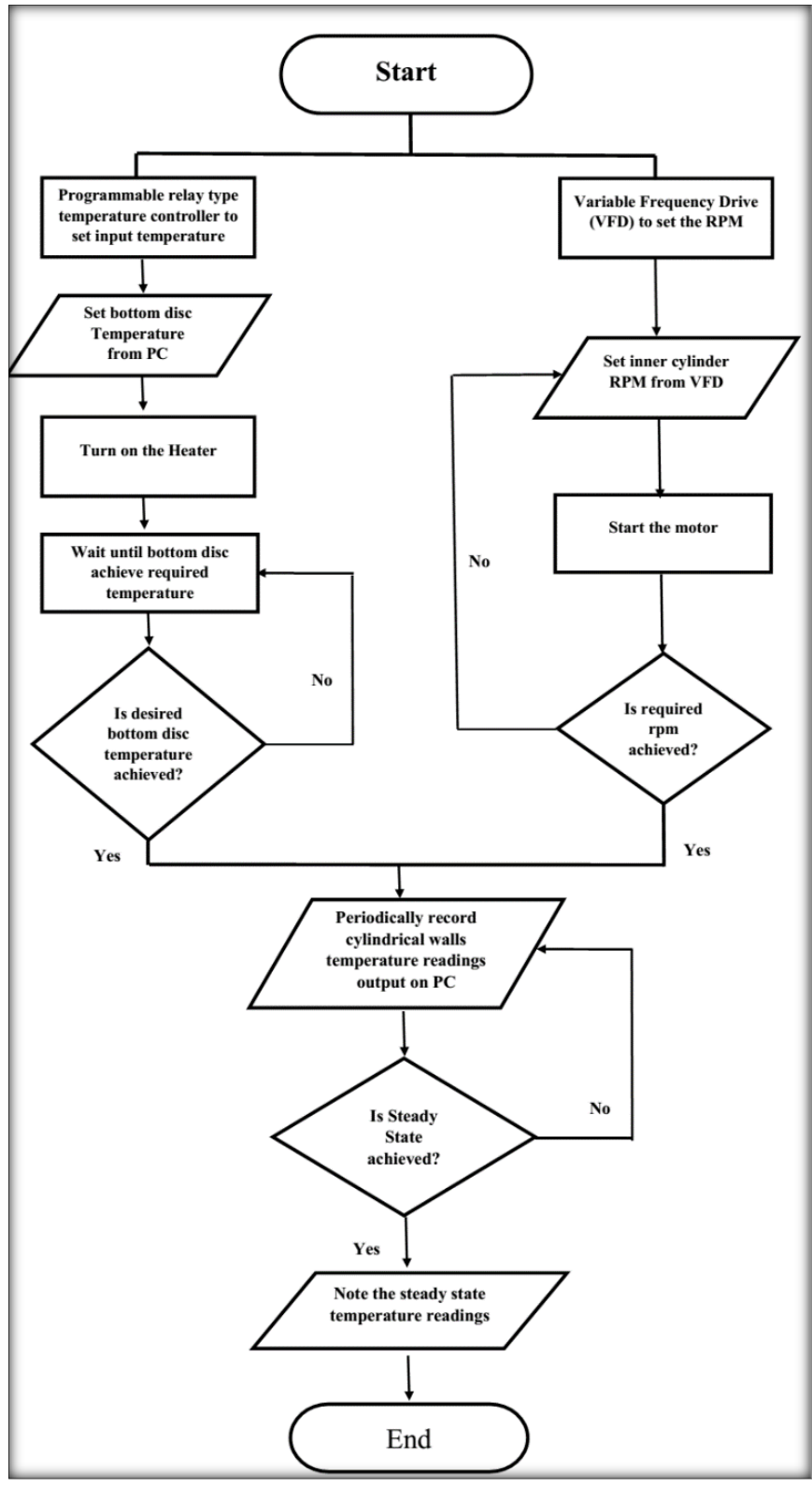

Figure 4. Schema of the experimental procedures

\subsection{Repeatability and error analysis}

There are always possibilities of some errors in the experimental studies. In this study, all the experiments were repeated at least three times and a repeatability analysis of measured wall temperatures is done to determine the range of errors in the measurements. It was observed that the steady state temperature values shown a slight difference in the range of 0 to $\pm 0.6 \mathrm{~K}$. Repeatability analysis in the form of maximum errors shown by temperature sensors of the inner and outer cylinder is tabulated in Table 4. Similarly, the errors in the plate disc temperatures are summarized in Figure 3. Temperature fluctuations for tripping and reactivation were recorded about $\pm 1.5 \mathrm{~K}$. The heater and controller arrangement produced almost a sinusoidal wave of temperature which oscillates above and below the required value of temperature. The sinusoidal waves for one set of experiments can be seen in Figure 3. While the errors in the measurements of RPMs were negligible because VFD helped to assign a certain frequency of the motor to the corresponding RPMs of the inner cylinder. Frequencies were assigned carefully after 3 test runs and a specific frequency for certain RPMs of the inner cylinder 
Table 4. Repeatability analysis of temperature sensors

\begin{tabular}{|l|c|c|c|c|c|c|c|c|c|}
\hline Sesnor & $\mathbf{T}_{\mathbf{1 h}}$ & $\mathbf{T}_{\mathbf{2 h}}$ & $\mathbf{T}_{\mathbf{3 h}}$ & $\mathbf{T}_{\mathbf{4 h}}$ & $\mathbf{T}_{\mathbf{5 h}}$ & $\mathbf{T}_{\mathbf{6 h}}$ & $\mathbf{T}_{7 \mathbf{h}}$ & $\mathbf{T}_{\mathbf{8 h}}$ & $\mathbf{T}_{\mathbf{9 h}}$ \\
\hline Max Error & 0.58 & 0.3 & 0.29 & 0.22 & 0.19 & 0.2 & 0.21 & 0.15 & 0.11 \\
\hline Sesnor & $\mathbf{T}_{1 \mathrm{c}}$ & $\mathbf{T}_{\mathbf{2 c}}$ & $\mathbf{T}_{\mathbf{3 c}}$ & $\mathbf{T}_{\mathbf{4 c}}$ & $\mathbf{T}_{\mathbf{5 c}}$ & $\mathbf{T}_{\mathbf{6 c}}$ & $\mathbf{T}_{7 \mathrm{c}}$ & $\mathbf{T}_{\mathbf{8 c}}$ & $\mathbf{T}_{\mathbf{9 c}}$ \\
\hline Max Error & 0.5 & 0.15 & $\mathbf{0 . 2 5}$ & $\mathbf{0 . 2}$ & $\mathbf{0 . 1 1}$ & $\mathbf{0 . 1 1}$ & $\mathbf{0 . 1 1}$ & $\mathbf{0}$ & $\mathbf{0 . 1}$ \\
\hline
\end{tabular}

\subsection{Data reduction}

Representation of the measured data using pertinent procedures with respect to suitable parameters is important. Data reduction techniques used in this research are following. Inner cylinder of the annulus is considered as hot wall and its temperature is taken as the average value of all the nine temperature sensors mounted on its external surface.

$T_{h}=\frac{T_{1 h}+T_{2 h}+T_{3 h}+T_{4 h}+T_{5 h}+T_{6 h}+T_{7 h}+T_{8 h}+T_{9 h}}{9}$

Similarly, the outer cylinder is considered as cold wall and its temperature is taken as the average value of all the nine temperature sensors mounted on its internal surface.

$T_{C}=\frac{T_{1 c}+T_{2 c}+T_{3 c}+T_{4 c}+T_{5 c}+T_{6 c}+T_{7 c}+T_{8 c}+T_{9 c}}{9}$

Relevant Non-dimensional parameters are also calculated from measured data, description of these parameters is following

Rotational Reynold's number of inner cylinder is calculated by the following relation:

$R e_{\Omega}=\frac{\Omega D_{H}^{2}}{2 v}$

where $\mathrm{D}_{\mathrm{H}}=\mathrm{D}_{\mathrm{o}}-\mathrm{D}_{\mathrm{i}}$

Non-dimensional length is calculated as follows:

$y=\frac{y^{*}}{L_{i}}$

Non-dimensional temperature is calculated by the following relation:

$\theta=\frac{T-T_{C}}{\Delta T}$

where $\mathrm{T}$ is variable temperature and $\Delta \mathrm{T}=\mathrm{T}_{\mathrm{h}}-\mathrm{T}_{\mathrm{c}}$

Nusselt number is an important parameter for convection heat transfer. Local $\mathrm{Nu}$ in this study is calculated by the relation used by Malik et al. [6] and given as follows:

$N u=\frac{h D_{H}}{k_{f}}=\left.\frac{d \theta}{d r}\right|_{r=0}$

Film temperature is mostly used to evaluate the thermal properties like thermal diffusivity of fluid, viscosity of fluid etc. In this study, film temperature is taken as follows:

$T_{f}=\frac{T_{y h}+T_{y c}}{2}$
Another important dimensionless parameter for free convection heat transfer is Grashof number and it is calculated by the following relation:

$G r=\frac{g \beta\left(T_{y h}-T_{y c}\right) D_{H}^{3}}{v^{2}}$

The non-dimensional parameter for buoyancy-driven flows is Rayleigh number, which is calculated by the following relation:

$R a=\frac{g \beta\left(T_{y h}-T_{y c}\right) D_{H}^{3}}{\alpha v}$

\section{RESULTS AND DISCUSSION}

This study was planned to investigate the heat transfer within a vertical cylindrical annulus when the inner cylinder of the enclosure was rotating while the enclosure was being heated from below with the help of a heated plate. This heating produced a buoyancy-driven flow leading to thermosyphon within the enclosure. The flow characteristics inside the enclosure were interesting and complex as it was external flow in nature with respect to the inner cylinder and internal flow with respect to the outer cylinder. The presence of rotation of the inner cylinder in this study made the case more exciting and worthy enough to be examined critically. The bottom and top surfaces of the enclosure were insulated, the heat generated by the bottom plate entered the annulus from the bottom and left the enclosure by walls of the outer cylinder. The heat was lost to an environment where the ambient temperature was 295 $\mathrm{K}$, air's Pr was 0.714 and the kinematic viscosity was $1.532 \mathrm{E}$ $5 \mathrm{~m}^{2} / \mathrm{s}$ [31].

\subsection{Quantitative thermal analysis}

A grave quantitative analysis of steady-state temperatures revealed that a competition between buoyancy-driven flow and rotational effects was sparked due to rotation of the inner cylinder. Logically, buoyancy effects were responsible for heat transfer in the axial direction while the rotational effects forced the heat to be transmitted in the radial direction. A summarized effect of this competition between the buoyancy and rotational effects inside the enclosure is described by the steady-state temperature differences in axial and radial directions.

For axial direction, variations in the steady-state temperature difference between the top and bottom sensor of the outer cylinder $\left(\mathrm{T}_{1 \mathrm{c}}-\mathrm{T}_{9 \mathrm{c}}\right)$ are analyzed. Figure 5 depicts that the temperature difference factor $\left(T_{1 c}-T_{9 c}\right)$ increases with the increasing values of $\operatorname{Re}_{\Omega}$. This increase in temperature difference indicates the suppression of the buoyancy effects at higher values of $\operatorname{Re}_{\Omega}$. Evidently, Figure 5 verifies the 
dominance of rotational effects over the buoyancy effects at higher $\operatorname{Re}_{\Omega}$.

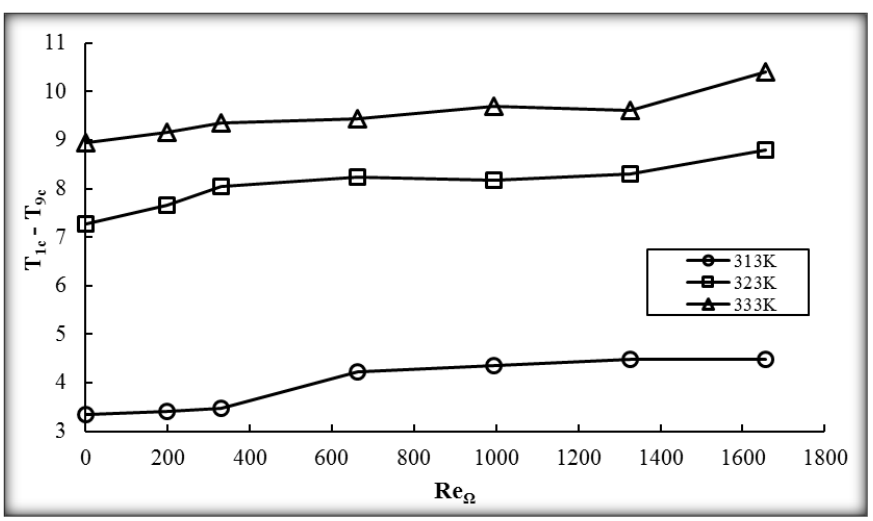

Figure 5. Evolution of $\mathrm{T}_{1 \mathrm{c}}-\mathrm{T}_{9 \mathrm{c}}$ with $R e_{\Omega}$

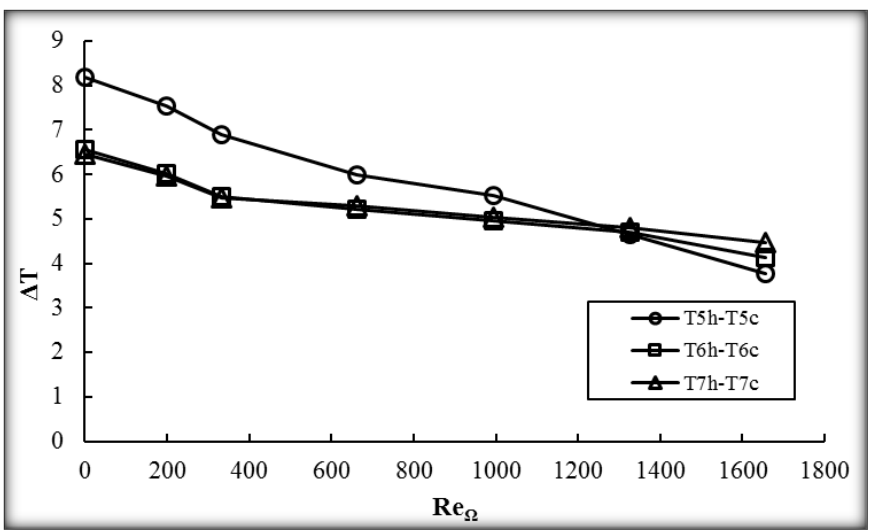

Figure 6. Evolution of $\Delta \mathrm{T}$ with $R e_{\Omega}$ at $\mathrm{T}_{\mathrm{b}}=333 \mathrm{~K}$

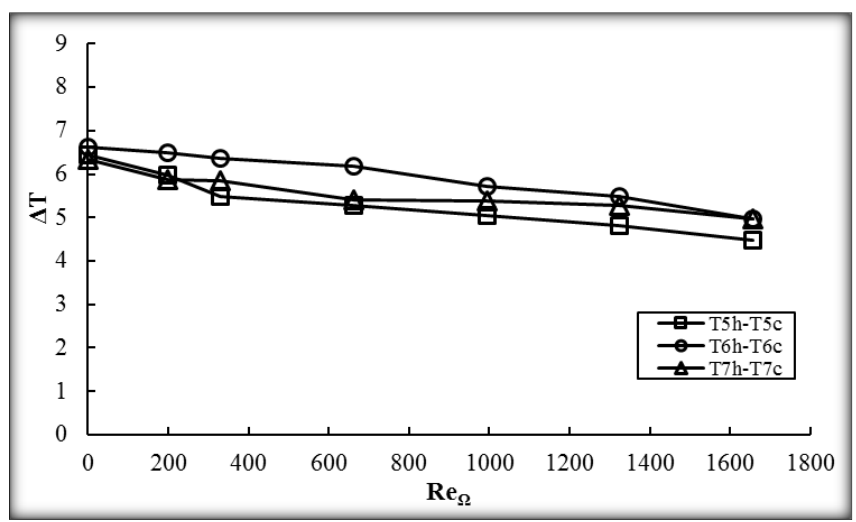

Figure 7. Evolution of $\Delta \mathrm{T}$ with $R e_{\Omega}$ at $\mathrm{T}_{\mathrm{b}}=323 \mathrm{~K}$

Similarly, analysis of the steady-state surface temperatures in the radial direction describes the dominance of rotational effects, but a critical view of temperature differences also illustrates another important outcome. Radial temperature difference values give an idea about the portions of the annulus where rotational effects were more influential. Figures 6, 7 and 8 show the steady-state temperature differences between the inner and outer cylinder at three points. These points are positions of temperature sensors $\mathrm{T}_{5}$ (mid-length point of the inner cylinder), $\mathrm{T}_{6}$ and $\mathrm{T}_{7}$. Temperature differences are plotted against $\operatorname{Re}_{\Omega}$. Portions where steady-state temperature differences are less; depict the more heat transfer in the radial direction. In other words, more the negative slope in the plots, stronger the heat transfer in the radial direction they present. A comparison of the plots indicates that more the temperature of the bottom plate, more the rotational effects extend towards the upper portion of the annulus.

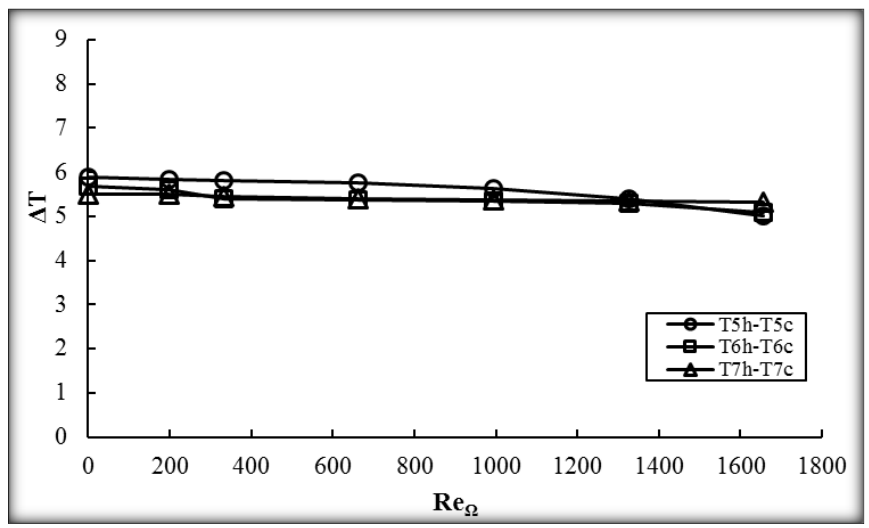

Figure 8. Evolution of $\Delta \mathrm{T}$ with $R e_{\Omega}$ at $\mathrm{T}_{\mathrm{b}}=313 \mathrm{~K}$

\subsection{Non-dimensional analysis}

Nusselt number is an important non-dimensional parameter which is used to express the heat transfer coefficient for convection heat transfer. Local $\mathrm{Nu}$ along the outer wall of the inner cylinder is calculated in this research. The study of the outer wall of the inner cylinder is important because it functioned as the source of convection heat transfer for the outer cylinder. The local $\mathrm{Nu}$ is calculated by using the relation in Eq. (6).

$\mathrm{Nu}$ variations with $\mathrm{Re}_{\Omega}$ and the dimensionless length is presented in the tabular form in Table 5. This study of $\mathrm{Nu}$ is also done for three bottom disc temperatures $(313 \mathrm{~K}, 323 \mathrm{~K}$, $333 \mathrm{~K}$ ). As expected, $\mathrm{Nu}$ is high near the bottom plate (heat source), but it decreases with the height as the distance from the heat source increased. The same trend of the local Nusselt number versus dimensionless distance for the stationary case was reported by Malik et al. [6]. The effect of rotation on the local $\mathrm{Nu}$ is very significant. As in case of rotation, the flow became complex and factors like centrifugal force, Coriolis effect etc. came into play. These effects instigated turbulence and vigorous mixing of fluid within the enclosure and significantly increased the heat transfer rate due to convection. So, $\mathrm{Nu}$ increased as $\mathrm{Re}_{\Omega}$ was increased, but the increase was not uniform and shown some variations. It can also be observed that the effect of rotation on local $\mathrm{Nu}$ is more prominent at the bottom portion of the annulus as compared to the top portion, but the location of this effect extends to a relatively higher portion of the annulus as the temperature of the bottom plate increases.

Rotation of the inner cylinder strongly affected the heat transport mechanisms especially near the base of the annulus i.e. near the heat source. For a better understanding of varying convective heat transport mechanisms, convective coefficient at base $h_{b}$ is plotted against varying $\operatorname{Re}_{\Omega}$ in Figure 9. Evidently low values of $h_{b}$ at low $\operatorname{Re}_{\Omega}$ infers the presence of free mode of convection. While around $10-15 \%$ increase in $\mathrm{h}_{\mathrm{b}}$ can be noticed at higher values of $\mathrm{Re}_{\Omega}$, suggesting a stronger transport mechanism such as forced convection. 
Table 5. Local $\mathrm{Nu}$ for non-dimensional length and $\boldsymbol{R} \boldsymbol{e}_{\Omega}$

\begin{tabular}{|c|c|c|c|c|c|c|c|c|}
\hline \multirow{2}{*}{$\begin{array}{l}\text { Bottom } \\
\text { Disc Temp. }\end{array}$} & \multirow{2}{*}{$\mathbf{y}$} & \multicolumn{7}{|c|}{ Local Nu } \\
\hline & & Stationary & $\operatorname{Re}_{\Omega}=199$ & $\operatorname{Re}_{\Omega}=331$ & $\mathrm{Re}_{\Omega}=663$ & $\mathrm{Re}_{\Omega}=994$ & $\operatorname{Re}_{\Omega}=1325$ & $\operatorname{Re}_{\Omega}=1660$ \\
\hline \multirow{9}{*}{333} & 0.1 & 26.1 & 26.9 & 27.7 & 28.5 & 29.3 & 31.6 & 32.8 \\
\hline & 0.2 & 17.4 & 18.0 & 18.7 & 19.9 & 21.0 & 22.4 & 23.5 \\
\hline & 0.3 & 12.0 & 12.5 & 13.0 & 13.4 & 14.1 & 14.4 & 14.8 \\
\hline & 0.4 & 8.7 & 8.7 & 8.9 & 8.6 & 8.7 & 8.8 & 9.0 \\
\hline & 0.5 & 5.5 & 5.4 & 5.3 & 4.8 & 4.8 & 4.0 & 3.5 \\
\hline & 0.6 & 2.4 & 2.2 & 1.9 & 1.4 & 1.1 & 0.5 & 0.2 \\
\hline & 0.7 & 1.6 & 1.2 & 0.8 & 0.4 & 0.1 & 0.9 & 1.3 \\
\hline & 0.8 & 1.5 & 0.9 & 0.1 & 0.6 & 1.3 & 2.2 & 1.7 \\
\hline & 0.9 & 0.8 & 0.3 & 0.4 & 1.0 & 0.3 & 0.2 & 0.2 \\
\hline \multirow{9}{*}{323} & 0.1 & 22.3 & 23.0 & 23.9 & 25.4 & 27.6 & 27.4 & 27.9 \\
\hline & 0.2 & 19.5 & 19.0 & 18.5 & 19.3 & 19.8 & 20.9 & 21.6 \\
\hline & 0.3 & 14.3 & 14.0 & 13.8 & 14.0 & 14.1 & 14.9 & 15.0 \\
\hline & 0.4 & 10.1 & 9.7 & 9.3 & 9.4 & 9.1 & 9.1 & 8.9 \\
\hline & 0.5 & 5.4 & 5.4 & 5.4 & 5.1 & 4.4 & 4.1 & 4.8 \\
\hline & 0.6 & 3.2 & 3.3 & 3.4 & 3.0 & 2.8 & 2.9 & 2.3 \\
\hline & 0.7 & 0.7 & 1.0 & 1.4 & 0.7 & 0.1 & 0.1 & 0.3 \\
\hline & 0.8 & 0.0 & 0.4 & 0.7 & 0.1 & 0.7 & 0.7 & 0.1 \\
\hline & 0.9 & 1.3 & 0.8 & 0.4 & 0.7 & 0.3 & 0.1 & 0.1 \\
\hline \multirow{9}{*}{313} & 0.1 & 19.9 & 20.7 & 20.9 & 21.6 & 21.9 & 21.8 & 22.2 \\
\hline & 0.2 & 16.4 & 16.8 & 17.3 & 16.2 & 15.4 & 15.3 & 17.1 \\
\hline & 0.3 & 12.0 & 12.4 & 12.9 & 12.4 & 12.8 & 12.9 & 14.2 \\
\hline & 0.4 & 9.3 & 8.7 & 8.0 & 8.2 & 7.7 & 8.0 & 8.2 \\
\hline & 0.5 & 7.2 & 6.5 & 5.7 & 5.0 & 4.8 & 4.9 & 4.7 \\
\hline & 0.6 & 4.9 & 4.6 & 4.3 & 4.1 & 4.2 & 4.3 & 4.4 \\
\hline & 0.7 & 3.3 & 3.3 & 3.3 & 3.5 & 3.8 & 3.6 & 2.9 \\
\hline & 0.8 & 2.7 & 2.8 & 3.0 & 3.7 & 3.8 & 3.9 & 2.4 \\
\hline & 0.9 & 1.9 & 2.3 & 2.6 & 3.4 & 3.6 & 3.3 & 1.9 \\
\hline
\end{tabular}

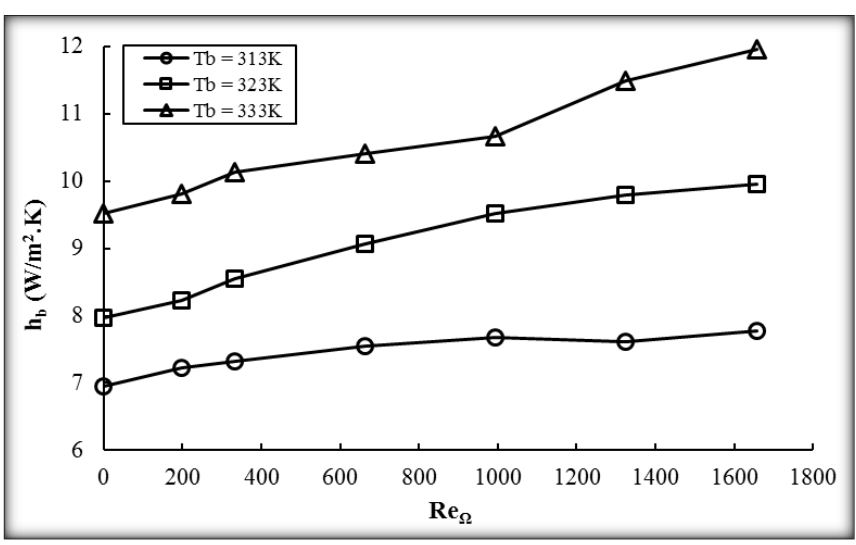

Figure 9. Variations of $h_{b}$ with $R e_{\Omega}$

To further investigate the dominant heat transport mechanism within the enclosure, a parameter $\mathrm{Gr} / \mathrm{Re}_{\mathbf{\Omega}}{ }^{2}$ is calculated. The presented result includes the ratio of average Gr for the complete length of the inner cylinder and square of $\operatorname{Re}_{\boldsymbol{\Omega}}$. Figure 10 presents the variation of $\mathrm{Gr} / \mathrm{Re}_{\boldsymbol{\Omega}}{ }^{2}$ with $\mathrm{Re}_{\boldsymbol{\Omega}}$. It is apparent that in three experimental runs for three different base plate temperatures, the trend is almost linear on a log-log scale. As $\mathrm{Gr} / \mathrm{Re}_{\Omega}{ }^{2}$ indicates the mechanism of heat transport [17], the trend clearly shows the influence of rotation on the transport mechanisms. Expectedly, at lower $\operatorname{Re}_{\Omega}$ i.e. low rotational speeds of the inner cylinder, value for the $\mathrm{Gr} / \mathrm{Re}_{\Omega}{ }^{2}$ are significantly greater than 1 . Here $\mathrm{Gr} / \mathrm{Re}_{\Omega}{ }^{2} \gg 1.0$, buoyancy-driven flows are dominant and free convection is main drive for heat transfer. For moderate values of $\mathrm{Re}_{\Omega}$, $\mathrm{Gr} / \mathrm{Re}_{\Omega}{ }^{2} \approx 1.0$ and that indicates the presence of a moderate transport mechanism such as mixed convection. While for higher values of $\operatorname{Re}_{\Omega}$, it is observed that $\mathrm{Gr} / \mathrm{Re}_{\Omega}{ }^{2} \ll 1.0$ which clearly marks that rotational effects are stronger and forced convection is the main element for heat transfer.

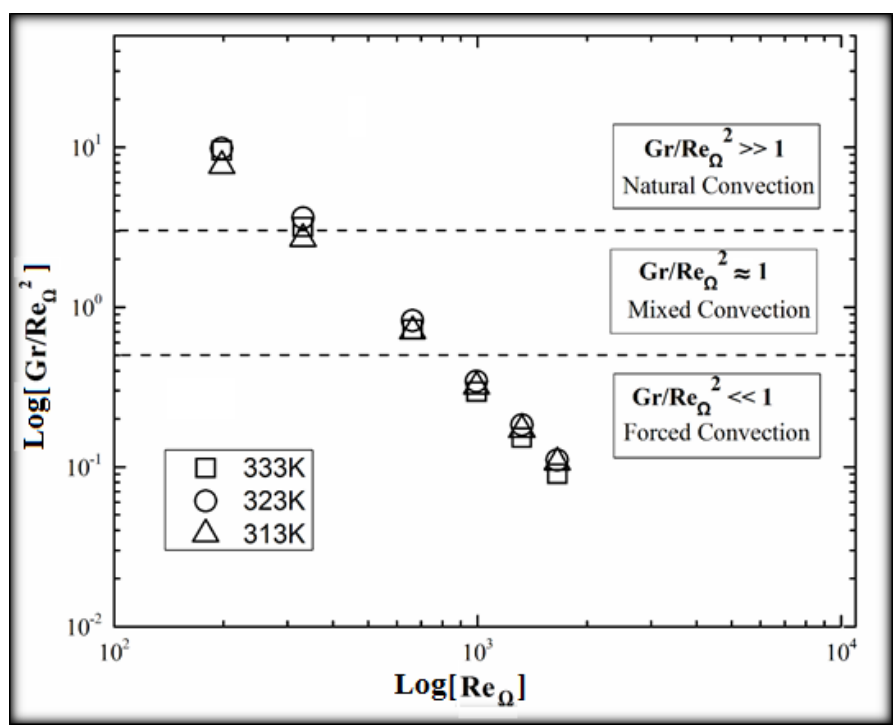

Figure 10. Variations of convective heat transport mechanisms with $R e_{\Omega}$

Similarly, Figure 12 summarizes the effect of different convective heat transport mechanisms on the base $\mathrm{Nu}$. As the forced convection is a stronger mode of heat transfer, the values of $\mathrm{Nu}_{\mathrm{b}}$ increase rapidly in the forced convection regime. Evidently and logically, this effect is bulging at higher temperatures of the bottom disc. 
Rayleigh number is also an important parameter for buoyancy-driven flows. Ra is often used to express the effects of buoyancy and natural convection. The expression of the Ra used in present research is given by Eq. (9)

Local $\mathrm{Ra}$ is plotted against local Nu. Figures 12, 13 and 14 show the plot for three different disc temperatures $(313,323$, $333 \mathrm{~K}$ ) at different $\mathrm{Re}_{\Omega}$.

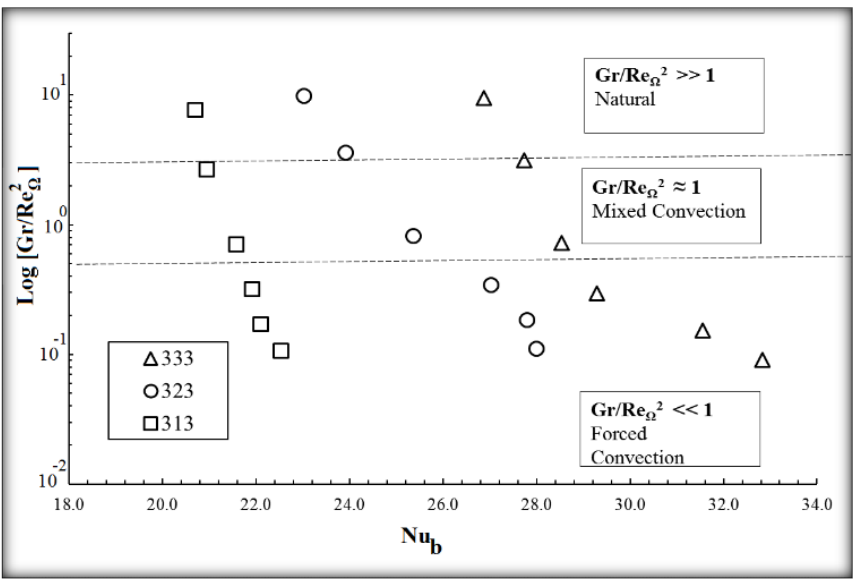

Figure 11. Evolution of $\mathrm{Nu}_{\mathrm{b}}$ against different convective heat transport mechanisms

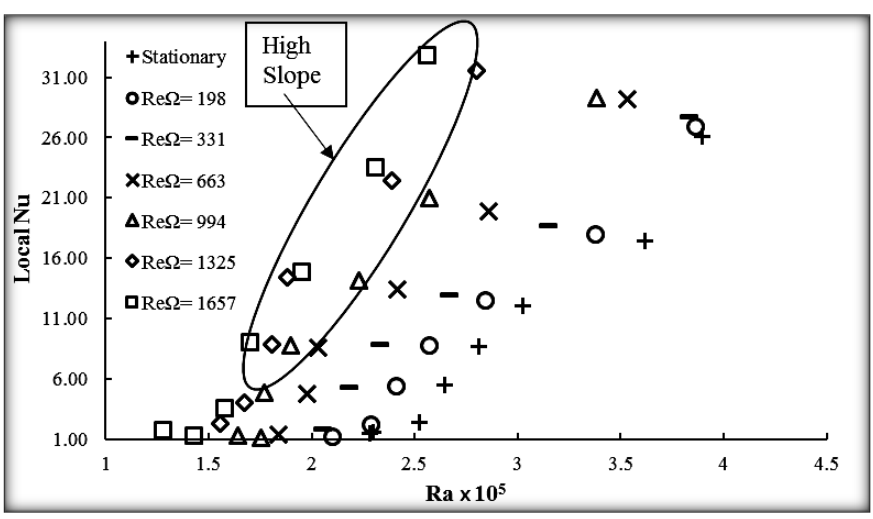

Figure 13. Evolution of Local Nu with Local Ra for bottom disc temp of $333 \mathrm{~K}$

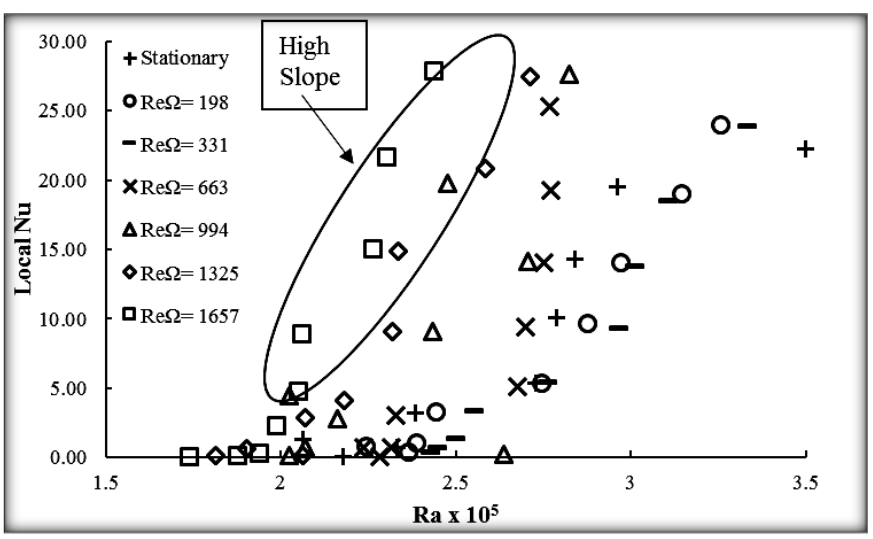

Figure 14. Evolution of Local Nu with Local Ra for bottom disc temp of $323 \mathrm{~K}$

Malik et al. [6] found that the local $\mathrm{Nu}$ has a direct relation with local Ra. Similarly, in this study, the plots of local Nu and local $\mathrm{Ra}$ show a direct relation between them and a uniform positive slope of lower $\operatorname{Re}_{\Omega}$ and stationary cases verifies this direct relation. This uniformly increasing slope indicates the presence of buoyancy effects. But with the increasing $\operatorname{Re}_{\Omega}$, the plots become steeper and indicates an important fact that at higher $\mathrm{Re}_{\Omega}$, the increase in local $\mathrm{Nu}$ at is not influenced by buoyancy effects rather than the increase is due to rotational effects of the inner cylinder. Hence at higher values of $\mathrm{Re}_{\Omega}$, local $\mathrm{Nu}$ tends to become independent of local $\mathrm{Ra}$. On the other hand, at higher bottom disc temperatures, buoyancy effects turn out to be stronger and the plots for higher $\mathrm{Re}_{\Omega}$ become relatively less steeper as compared to lower bottom disc temperatures.

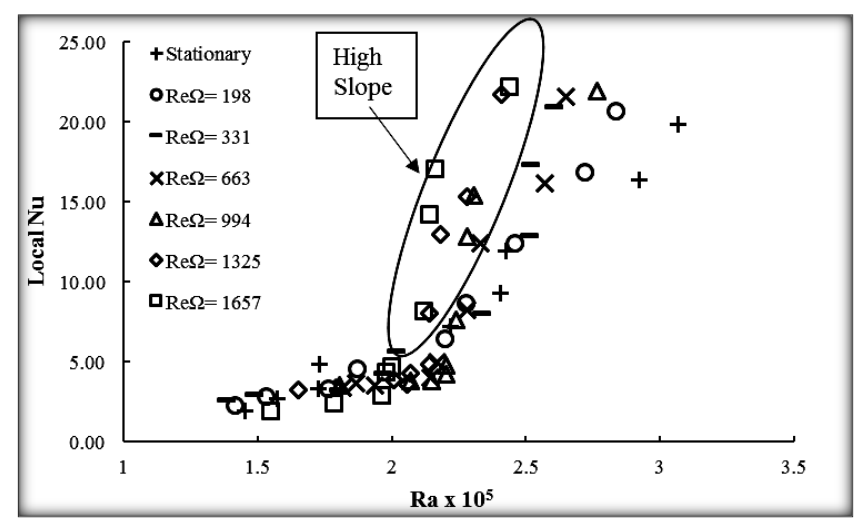

Figure 15. Evolution of Local $\mathrm{Nu}$ with Local Ra for bottom disc temp of $313 \mathrm{~K}$

\section{CONCLUSIONS}

The experimental study of heat transfer in a bottom heated vertical and concentric annulus is presented in this research. The inner cylinder in the annulus was being rotated for $a \mathrm{Re}_{\Omega}$ of 0 to 1660 while the temperature of the bottom heated plate temperature was kept at three different values $(313,323,333$ $\mathrm{K})$. A steady-state investigation was done and from the results of this study following conclusions can be drawn.

(1) Rotation of the inner cylinder significantly affected the heat transfer within the annulus having buoyancy-driven flow, as the inner cylinder rotated, the buoyancy effect of bottom heating was reduced and dominated by the rotational effect of the inner cylinder. In other words, rotation of inner cylinder changed the dominant direction of heat transfer from axial to radial. Almost $15 \%$ increase in Local $\mathrm{Nu}$ values was seen at higher values of $\mathrm{Re}_{\Omega}$.

(2) Section of the annulus more influenced by rotation depend upon the temperature of the bottom heated plate. When the bottom disc temperature was $313 \mathrm{~K}$, rotation strongly influence the heat transfer in bottom half of the annulus only, but for $333 \mathrm{~K}$ of bottom plate temperature the effect of rotation extended upwards to almost $3 / 4^{\text {th }}$ of the length of annulus. Hence, more the temperature of the heated plate, more the rotational effects was extended towards the upper portion of the annulus.

(3) Rotation of the inner cylinder effectively altered the dominant heat transport mechanism within the enclosure. Parameter $\mathrm{Gr} / \mathrm{Re}_{\mathbf{\Omega}}{ }^{2}$ indicated that the heat transport within the annulus was free convection when $\mathrm{Re}_{\Omega} \leq 500$, mixed convection 
when $500<\operatorname{Re}_{\Omega}<1000$ and forced convection when $\operatorname{Re}_{\Omega} \geq 1000$.

(4) At lower values of $\mathrm{Re}_{\Omega}$, local $\mathrm{Nu}$ within the enclosure shown a direct relation with local Ra. But this relation deteriorated as $\mathrm{Re}_{\Omega}$ increased. Subsequently, at higher values of $\mathrm{Re}_{\Omega}$, local $\mathrm{Nu}$ seemed to become independent of local Ra.

\section{ACKNOWLEDGMENTS}

This study was funded and supported by Mechanical Engineering Department, University of Engineering and Technology Taxila, Pakistan, which is gratefully acknowledged.

\section{REFERENCES}

[1] Jaluria Y. (2008). Design and optimization of thermal systems. Boca Raton. Fla. [u.a.]: CRC Press.

[2] Moiseeva L, Cherkasov S. (1997). Stationary freeconvection heat exchange in a cylindrical tank with uniform heat supply and simultaneous heat removal through local sinks. Teplofizika Vysokikh Temperatur 35: 564-569.

[3] Kee R, Landram C, Miles J. (1976). Natural convection of a heat-generating fluid within closed vertical cylinders and spheres. Journal of Heat Transfer 98: 55-61. https://doi:10.1115/1.3450469

[4] Keyhani M, Kulacki F, Christensen R. (1983). Free convection in a vertical annulus with constant heat flux on the inner wall. Journal of Heat Transfer 105: 454-459. https://doi:10.1115/1.3245606

[5] Lipkea WH, Springer GS. (1968). Heat transfer through gases contained between two vertical cylinders at different temperatures. International Journal of Heat and Mass Transfer 11: 1341-1350. https://doi.org/10.1016/0017-9310(68)90179-8

[6] Malik AH, Alvi M, Khushnood S, Mahfouz F, Ghauri M, Shah A. (2012). Experimental study of conjugate heat transfer within a bottom heated vertical concentric cylindrical enclosure. International Journal of Heat and Mass Transfer 55: 1154-1163. https://doi.org/10.1016/j.ijheatmasstransfer.2011.09.055

[7] Sankar M, Park Y, Lopez JM, Do Y. (2011). Numerical study of natural convection in a vertical porous annulus with discrete heating. International Journal of Heat and Mass Transfer 54: 1493-1505. https://doi.org/10.1016/j.ijheatmasstransfer.2010.11.043

[8] Alipour M, Hosseini R, Rezania A. (2013). Radius ratio effects on natural heat transfer in concentric annulus. Experimental Thermal and Fluid Science 49: 135-140. https://doi.org/10.1016/j.expthermflusci.2013.04.011

[9] Hosseini R, Ramezani M, Mazaheri MR. (2009). Experimental study of turbulent forced convection in vertical eccentric annulus. Energy Conversion and Management 50: 2266-2274. https://doi.org/10.1016/j.enconman.2009.05.002

[10] Mohammed HA, Campo A, Saidur R. (2010). Experimental study of forced and free convective heat transfer in the thermal entry region of horizontal concentric annuli. International Communications in Heat $\begin{array}{llll}\text { and } & \text { Mass } & \text { 739-747. }\end{array}$ https://doi.org/10.1016/j.icheatmasstransfer.2010.04.00 7

[11] Angeli D, Barozzi G, Collins M, Kamiyo O. (2010). A critical review of buoyancy-induced flow transitions in horizontal annuli. International Journal of Thermal Sciences 49: 2231-2241. https://doi.org/10.1016/j.ijthermalsci.2010.08.002

[12] Jeng TM, Tzeng SC, Lin CH. (2007). Heat transfer enhancement of Taylor-Couette-Poiseuille flow in an annulus by mounting longitudinal ribs on the rotating inner cylinder. International Journal of Heat and Mass Transfer 50: 381-390. https://doi.org/10.1016/j.ijheatmasstransfer.2006.06.005

[13] Astill K. (1964). Studies of the developing flow between concentric cylinders with the inner cylinder rotating. Journal of Heat Transfer 86: 383-391. https://doi:10.1115/1.3688703

[14] Ball K, Farouk B, Dixit V. (1989). An experimental study of heat transfer in a vertical annulus with a rotating inner cylinder. International Journal of Heat and Mass Transfer 32: 1517-1527. https://doi.org/10.1016/00179310(89)90073-2

[15] Lee J, Kang SH, Son YS. (1999). Experimental study of double-diffusive convection in a rotating annulus with lateral heating. International journal of Heat and Mass Transfer 42: 821-832. https://doi.org/10.1016/S00179310(98)00226-9

[16] Fu WS, Cheng CS, Shieh WJ. (1994). Enhancement of natural convection heat transfer of an enclosure by a rotating circular cylinder. International Journal of Heat and Mass Transfer 37: 1885-1897. https://doi.org/10.1016/0017-9310(94)90329-8

[17] Misirlioglu A. (2006). The effect of rotating cylinder on the heat transfer in a square cavity filled with porous medium. International Journal of Engineering Science 44: 1173-1187. https://doi.org/10.1016/j.ijengsci.2006.07.008

[18] Roslan R, Saleh H, Hashim I. (2012). Effect of rotating cylinder on heat transfer in a square enclosure filled with nanofluids. International Journal of Heat and Mass Transfer 55: 7247-7256. https://doi.org/10.1016/j.ijheatmasstransfer.2012.07.051

[19] Liao CC, Lin CA. (2014). Mixed convection of a heated rotating cylinder in a square enclosure. International Journal of Heat and Mass Transfer 72: 9-22. https://doi.org/10.1016/j.ijheatmasstransfer.2013.12.081

[20] Paroncini M, Corvaro F, Padova M. (2006). Study and analysis of the influence of a small heating source positioned on the natural convective heat transfer in a square cavity. WSEAS Transaction on Heat and Mass Transfer 1: 461-466.

[21] Aydin O, Yang WJ. (2000). Natural convection in enclosures with localized heating from below and symmetrical cooling from sides. International Journal of Numerical Methods for Heat \& Fluid Flow 10: 518-529. https://doi.org/10.1108/09615530010338196

[22] Kuznetsov GV, Sheremet MA. (2011). Conjugate natural convection in an enclosure with a heat source of constant heat transfer rate. International Journal of Heat and Mass Transfer 54: 260-268. https://doi.org/10.1016/j.ijheatmasstransfer.2010.09.046

[23] Kang S, Choi H, Lee S. (1999). Laminar flow past a rotating circular cylinder. Physics of Fluids 11: 33123321. https://doi.org/10.1063/1.870190 
[24] Özerdem B. (2000). Measurement of convective heat transfer coefficient for a horizontal cylinder rotating in quiescent air. International Communications in Heat and Mass Transfer 27: 389-395. https://doi.org/10.1016/S0735-1933(00)00119-6

[25] Paramane SB, Sharma A. (2009). Numerical investigation of heat and fluid flow across a rotating circular cylinder maintained at constant temperature in 2D laminar flow regime. International Journal of Heat and Mass Transfer 52: 3205-3216. https://doi.org/10.1016/j.ijheatmasstransfer.2008.12.031

[26] Nagarajan R, Dhanasekaran R. (2013). Implementation of wireless data transmission in monitoring and control. in Communications and Signal Processing (ICCSP). 2013 International Conference on, 2013, pp. 83-87. https://10.1109/iccsp.2013.6577020

[27] Sehgal VK, Chauhan DS, Sharma R. (2008). Smart wireless temperature data logger using IEEE 802.15. 4/ZigBee protocol. In TENCON 2008-2008 IEEE Region 10 Conference, pp. 1-6. https:// 10.1109/TENCON.2008.4766744

[28] Borwankar AA, Ladkat AS, Mhetre MR. (2015). Thermal Transducers Analysis.

[29] Instruments T. (1999). LM35 Precision Centigrade Temperature Sensors. LM35 datasheet.

[30] Datasheet C. (2006). 2.4 GHz IEEE 802.15. 4/ZigBeeready RF Transceiver. Chipcon products from Texas Instruments.

[31] Yunus AC. (2003). Heat transfer: a practical approach. MacGraw Hill, New York.

\section{NOMENCLATURE}

$\mathrm{D}_{\mathrm{i}} \quad$ Diameter of the inner cylinder $(\mathrm{m})$

$\mathrm{D}_{\mathrm{o}} \quad$ Diameter of the outer cylinder $(\mathrm{m})$
$\mathrm{D}_{\mathrm{H}} \quad$ Hydraulic diameter of the annulus (m)

g Gravitational acceleration $\left(9.81 \mathrm{~m} / \mathrm{s}^{2}\right)$

Gr Grashof Number

h Heat transfer coefficient $\left(\mathrm{W} / \mathrm{m}^{2} . \mathrm{K}\right)$

$\mathrm{K}_{\mathrm{f}} \quad$ Air thermal conductivity (W/m.K)

$\mathrm{L}_{\mathrm{i}} \quad$ Length of inner cylinder (m)

$\mathrm{L}_{\mathrm{o}} \quad$ Length of outer cylinder (m)

$\mathrm{Nu} \quad$ Nusselt number

Pr Prandtl number

$\mathrm{r}^{*} \quad$ Radius of the annulus (m)

$r \quad$ Dimensionless radius of the annulus

$\mathrm{Ra} \quad$ Rayleigh number

Re Reynolds number

$\operatorname{Re}_{\boldsymbol{\Omega}} \quad$ Rotational Reynolds number

$\mathrm{T}_{\mathrm{h}} \quad$ Average Temperature of hot inner cylinder (K)

$\mathrm{T}_{\mathrm{c}} \quad$ Average Temperature of cold outer cylinder (K)

$\mathrm{T}_{\mathrm{yh}} \quad$ Local temperature of hot inner cylinder $(\mathrm{K})$

$\mathrm{T}_{\mathrm{yc}} \quad$ Local temperature of cold outer cylinder $(\mathrm{K})$

$\mathrm{y}^{*} \quad$ Vertical distance from the heat source $(\mathrm{m})$

y Dimensionless vertical distance from the heat source

\section{Greek symbols}

u kinematic viscosity $\left(\mathrm{m}^{2} / \mathrm{s}\right)$

$\Omega \quad$ Rotational speed (1/s)

\section{Subscripts}

(1-9) Temperature sensors

b base

f film

\section{Abbreviations}

RPM Revolutions per minute

VFD Variable Frequency Driv 